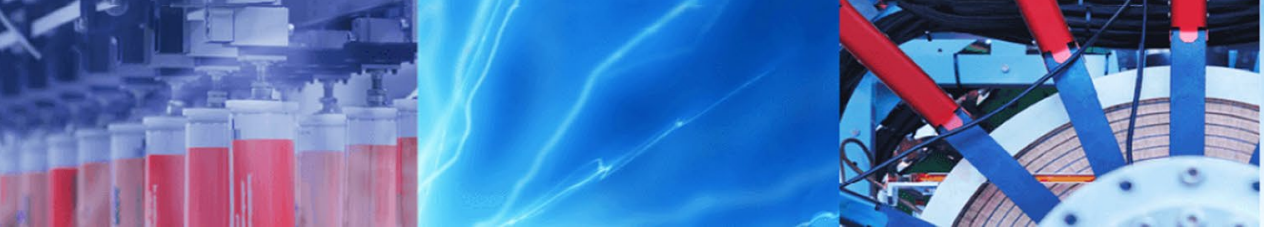

Research Article

\title{
Effect of annealing under different atmospheres of CZTS thin films as absorber layer for solar cell application
}

\author{
Samia Chamekh ${ }^{1}$ (D) Naoufel Khemiri ${ }^{1} \cdot$ Mounir Kanzari ${ }^{1,2}$
}

Received: 6 November 2019 / Accepted: 30 July 2020 / Published online: 13 August 2020

(c) Springer Nature Switzerland AG 2020

\begin{abstract}
The influence of annealing under several atmospheres on the structural and optical properties of $\mathrm{Cu}_{2} \mathrm{ZnSnS}_{4}$ (CZTS) thin films was investigated. Thin films were deposited on ordinary glass substrates by vacuum thermal evaporation method. In order to optimize the growth of CZTS films, the samples were annealed under different atmospheres: vacuum, nitrogen $\left(\mathrm{N}_{2}\right)$, Sulfur $\left(\mathrm{S}_{2}\right)$ and under vacuum followed by sulfuration. The structural study of CZTS films was carried out using the $\mathrm{X}$-ray diffraction. The spectra indicated the improvement of the crystalline quality of CZTS films after the thermal treatments. All annealed films exhibited a preferential orientation along the (112) plane. The optoelectronic properties of CZTS thin films were investigated using UV-Visible spectrophotometry. The optical study of annealed samples revealed a high absorption coefficient that exceeded $10^{4} \mathrm{~cm}^{-1}$ and a band gap in the range of $1.48-1.56 \mathrm{eV}$.
\end{abstract}

Keywords $\mathrm{Cu}_{2} \mathrm{ZnSnS}_{4} \cdot$ Thermal evaporation · Annealing process · Optical properties · Structural properties

\section{Introduction}

Currently, research in the solar cells field is one of the fastest growing renewable technologies [1]. Among various types of solar cells, $\mathrm{CIGS}\left(\mathrm{Culn}_{\mathrm{x}} \mathrm{Ga}_{1-x} \mathrm{~S}(\mathrm{Se})_{2}\right)$ and $\mathrm{CdTe}$ solar cells have attracted a lot of interest thanks to their high efficiencies 25 and $22.1 \%$ [2]. However, the reliability of CIGS and CdTe based solar cells is facing a hard task because of the scarcity of several constituents such as Indium (In) and germanium (Ga) [3] and the toxicity of Cadmium $(C d)[3,4]$. It is in this context, scientists were oriented in developing a new generation of thin film solar cells composed of low-cost and eco-friendly materials. Thanks to its optoelectronic properties, the quaternary chalcogenide family $\mathrm{Cu}_{2} \mathrm{XSnS}_{4}(\mathrm{X}=\mathrm{Ni}, \mathrm{Zn}, \mathrm{Co}, \mathrm{Mn}, \mathrm{Fe})$ [5-7] are chosen to be the promising group of materials for use as absorber layer for photovoltaic application [6]. Among the chalcogenide family, the $\mathrm{Cu}_{2} \mathrm{ZnSnS}_{4}$ (CZTS) is considered one of the most promising candidates owing to its p-type electrical conductivity, its high absorption coefficient of about $10^{4} \mathrm{~cm}^{-1}$ in the visible light region $[8$, 9] and its direct band gap of about $1.5 \mathrm{eV}[9,10]$. Many routes have been undertaken to elaborate CZTS thin films, whether chemical $[11,12]$ or physical techniques $[13,14]$. Among all these techniques, the thermal evaporation under vacuum has the advantage of providing high purity film, high deposition rate and low cost elaboration [15].

There are various reports about CZTS solar cells, where they identified the key issues to determine the properties of the CZTS absorber layer such as phase diagram, crystal structure, chemical composition, secondary phases and optical properties. In 2019, Olgar [16] has investigated the effect of sulfurization time and temperature on CZTS thin films and considered that sulfurization at $560^{\circ} \mathrm{C}$ for $60 \mathrm{~s}$ are the most promising conditions for CZTS growth. In the same context, Shin et al. [17] have reported the effect of

$\triangle$ Samia Chamekh, samia.chamekh@enit.utm.tn; Naoufel Khemiri, khemirinaoufel@gmail.com; Mounir Kanzari, mounir.kanzari@ipeit.rnu.tn| ${ }^{1}$ University of Tunis El Manar National Engineering School of Tunis, Photovoltaic and Semiconductor Materials Laboratory, Tunis, Tunisia.

2IPEITunis, University of Tunis, Montfleury, Tunis, Tunisia. 
stacking order in the precursor thin films and found out that the following order: $\mathrm{Cu} / \mathrm{SnS}_{2} / \mathrm{ZnS} /$ glass has a single phase CZTS contrary to other stacking order combinations.

In the present study, First, we have studied the structural properties of CZTS powder, then we have investigated the XRD patterns of CZTS thins films annealed under different atmospheres. Finally, we have studied the optical properties of the elaborated thin films and extracted their band gap and absorption coefficient. The aim of our work is to investigate the effect of the annealing atmosphere on structural and optical properties of CZTS in order to optimize the growth conditions of CZTS thin films to obtain a suitable absorber layer for earth abundant and non-toxic solar cells.

\section{Experimental details}

\subsection{Fabrication of $\mathrm{Cu}_{2} \mathrm{ZnSnS}_{4}$ (CZTS) powder}

The elemental constituents respectively: copper (Cu), zinc $(\mathrm{Zn})$, tin (Sn) and sulphur (S) with purity, over $99 \%$ were mixed according to stoichiometry amounts of $\mathrm{Cu}_{2} \mathrm{ZnSnS}_{4}$. Then, this mixture was loaded in a quartz tube. The tube was already cleaned by concentrated acid, rinsed in distilled water, then with acetone and finally dried for $30 \mathrm{~min}$ in over at $150{ }^{\circ} \mathrm{C}$. After, the quartz tube containing the pure elements pre-sealed under vacuum was placed in a furnace (type Nabertherm-Germany). First, the furnace temperature was increased with slow rate $\left(20 \mathrm{~h} /{ }^{\circ} \mathrm{C}\right)$ until $600^{\circ} \mathrm{C}$, then, the temperature was kept constant for $24 \mathrm{~h}$. After, the temperature was increased again up to $1000^{\circ} \mathrm{C}$ for $20 \mathrm{~h}$ and then it was kept constant for $48 \mathrm{~h}$. Finally, the temperature was decreased to $800{ }^{\circ} \mathrm{C}$ with a rate of $20 \mathrm{~h} /{ }^{\circ} \mathrm{C}$. The furnace was switched and the tube was allowed to cool naturally to room temperature. The formed ingot presented gray color. Figure 1 shows the obtained CZTS ingot. The CZTS ingot was crushed until obtaining a fine powder.

\subsection{Fabrication of $\mathrm{Cu}_{2} \mathrm{ZnSnS}_{4}$ (CZTS) thin films}

CZTS thin films were deposited onto no heated glass substrates, ultrasonically cleaned in the deionized water, acetone, ethanol, and steamed at $150^{\circ} \mathrm{C}$ for $20 \mathrm{~min}$, by thermal evaporation technique under vacuum. This technique relies on two variations of pressure: primary vacuum of $10^{-3}$ Torr, after, a secondary vacuum of $10^{-6}$ Torr which is kept constant during the deposition of our layers. Tungsten boat was used as evaporator source. After the deposition, in order to improve the crystalline quality of the films, all layers were annealed under 4 different atmospheres: $\mathrm{N}_{2}$ atmosphere (sample $\mathrm{S}-1$ ), $\mathrm{N}_{2}+\mathrm{S}_{2}$ atmosphere (sample $\mathrm{S}-2$ ),

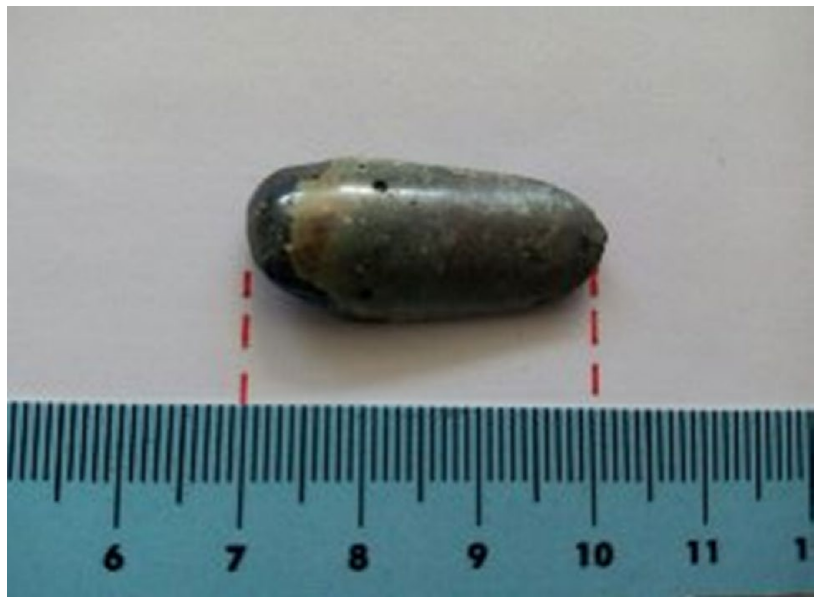

Fig. 1 CZTS ingot

under vacuum (sample S-3) and sulfur atmosphere followed by vacuum annealing (Sample S-4). The as-deposited sample is referred (S-0). The sulfuration process of the films was performed in a tubular furnace using $0.04 \mathrm{~g}$ of elemental sulphur (99.99\%), under azote atmosphere during $30 \mathrm{~min}$ at temperature of $400^{\circ} \mathrm{C}$. The annealing temperature was kept constant at $400^{\circ} \mathrm{C}$ for $2 \mathrm{~h}$. The annealing temperature was chosen based on our previous experiments. Indeed, we remarked that temperature superior to $400^{\circ} \mathrm{C}$ causes surface damages. After annealing, the films were allowed to cool naturally and were further characterized for their structural and optical properties.

\subsection{Characterization methods}

The structural properties of CZTS powder and films were analyzed by X-ray diffraction (XRD) operated in the $2 \theta$ range from $20^{\circ}$ to $90^{\circ}$ on an X'Pert PRO PANalytical diffractometer in Bragg-Brentano geometry $(\theta / 2 \theta)$ with CuKa radiation $\left(\lambda=1.5406 \AA\right.$ ) using a step size of $0.02^{\circ}$ and a step time of $1 \mathrm{~s}$. The optical analysis was obtained by recording the transmission and the reflexion spectra of the samples using a Schimadzu UV 3100 double beam spectrophotometer equipped with an integrating sphere (LISR 3200) and which wavelength ranges from $300 \mathrm{~nm}$ to $1800 \mathrm{~nm}$. The films thickness is measured using the interference fringes method [18].

\section{Results}

\subsection{Structural properties of $\mathrm{Cu}_{2} \mathrm{ZnSnS}_{4}$ powder}

Figure 2 shows the XRD pattern of the synthesized CZTS powder. Figure 2 reveals the presence of the CZTS kesterite 


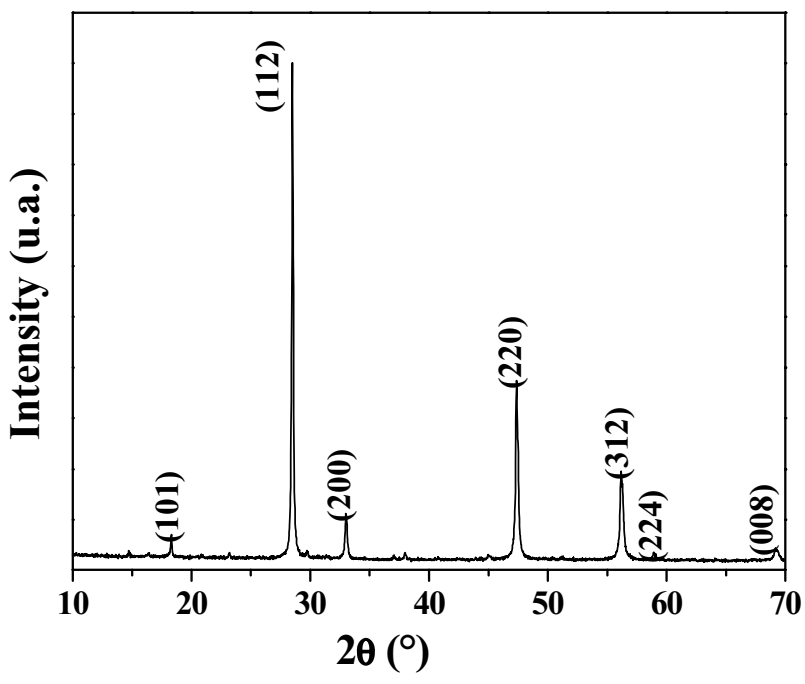

Fig. 2 XRD pattern of CZTS powder

phase proved by the presence of the principle diffraction peaks $2 \theta=28.51^{\circ}$ and $47.29^{\circ}$ corresponding to preferential orientations along (112) and (220) planes, respectively.

\subsection{Structural properties of $\mathrm{Cu}_{2} \mathrm{ZnSnS}_{4}$ thin films}

Figure 3 shows the XRD pattern of as-deposited CZTS thin film (S-0), which presents a global amorphous aspect. However, all annealed films are polycrystalline and present 4 diffraction peaks at $2 \theta=28.55^{\circ}, 33.08^{\circ}, 47.44^{\circ}$ and $56.27^{\circ}$ corresponding, respectively, to the (112), (200), (220) and (312) reticular planes (JCPD card No. 00-026-0575). The lattice parameters were calculated using the inter-reticular distance $d_{h k l}$ formula:

$d_{h k l}^{2}=a^{2} /\left(h^{2}+\left(k^{2} / 2\right)\right)+\left(I^{2} / c^{2}\right)$

where $\mathrm{a}$ and $\mathrm{c}$ are the lattice parameters and $\mathrm{hkl}$ are miller indexes.

The crystallite size is calculated using Debye-Scherrer equation $[19,20]$ :

$\mathrm{D}=0.9 \lambda / \beta \cos \theta$

where $D$ is the crystallite size, $\lambda$ is the wavelength of the incident $X$-ray source, $\beta$ is the full width at half maximum $x(F W H M)$ and $\theta$ is the Bragg angle.

The structural properties of a thin film may be affected with unfavourable factors such as micsostrain $(\varepsilon)$ and dislocation density $(\delta)$. Theses defaults may occur as a result of a geometric mismatch between the films and the crystalline lattice [21]. The microstrain was evaluated using the following relation $[19,22]$ :

$\varepsilon=\beta / 4 \tan \theta$

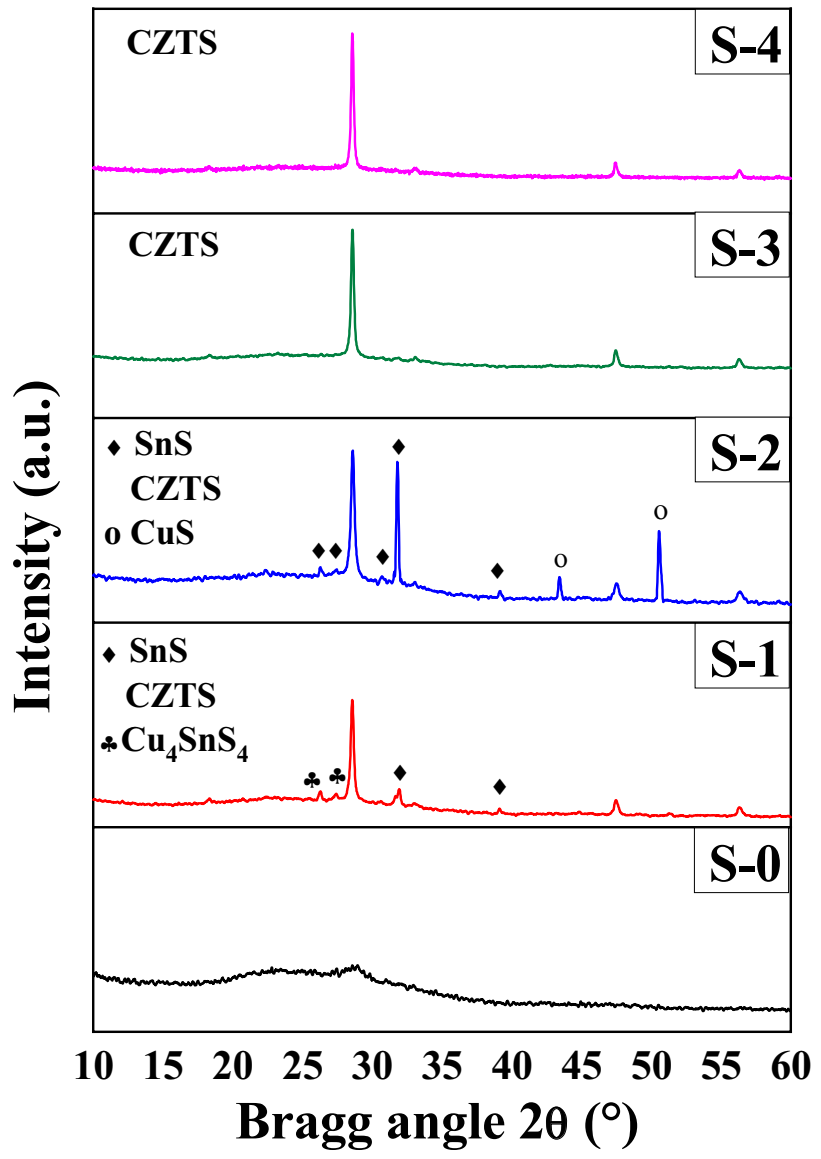

Fig. 3 XRD pattern of CZTS thin films annealed under different atmospheres

The dislocation density $\delta$ was estimated using the relation [19]:

$\delta=1 / D^{2}$

The structural parameters are summarized in Table 1.

Table 1 Structural properties of CZTS thin films annealed under different atmospheres

\begin{tabular}{|c|c|c|c|c|c|}
\hline \multirow[t]{2}{*}{ Sample } & \multicolumn{5}{|c|}{ Structural properties } \\
\hline & $2 \theta\left(^{\circ}\right)$ & $\mathrm{D}(\mathrm{nm})$ & $\delta\left(10^{14} \mathrm{~m}^{2}\right)$ & $\varepsilon$ & $\begin{array}{l}a=b \\
c\end{array}$ \\
\hline S-1 & 28.61 & 32.84 & 09.26 & 0.24 & $\begin{array}{l}a=b=5.41 \\
c=11.86\end{array}$ \\
\hline S-2 & 28.65 & 29.01 & 11.87 & 0.27 & $\begin{array}{l}a=b=5.41 \\
c=11.84\end{array}$ \\
\hline$S-3$ & 28.58 & 33.09 & 09.12 & 0.24 & $\begin{array}{l}a=b=5.51 \\
c=12.09\end{array}$ \\
\hline S-4 & 28.55 & 37.95 & 06.94 & 0.21 & $\begin{array}{l}a=b=5.41 \\
c=11.89\end{array}$ \\
\hline
\end{tabular}




\subsection{Optical properties of $\mathrm{Cu}_{2} \mathrm{ZnSnS}_{4}$ thin films}

\subsubsection{Optical transmission and reflexion}

Figures 4 and 5 display the optical transmission and reflexion spectra of CZTS thin films, respectively.

The optical transmission presents an oscillatory behaviour for all the annealed samples due to the multiple reflexions on the surfaces of the thin film [23], which proves the uniformity of thickness and the homogeneity of CZTS thin films.

The optical transmission of the annealed samples is very important and reaches $82 \%$ for the CZTS thin films annealed in Nitrogen atmosphere. However, the reflectance doesn't exceed $60 \%$ for all samples.

\subsubsection{Absorption coefficient and band gap}

The absorption coefficient a was estimated from the Transmission $(\mathrm{T})$ and Reflexion (R) data using the following relation $[23,24]$

$\alpha=\frac{1}{d} \ln \left(\frac{(1-R)^{2}}{T}\right)$

The Absorption coefficients of CZTS thin films annealed at different atmospheres as a function of incident photon energy are illustrated in Fig. 6. For all films, the absorption coefficient is clearly high and larger than $10^{4} \mathrm{~cm}^{-1}$ for incident photon energy range from 1.2 to $3 \mathrm{eV}$.

The optical band gap $E_{g}$ of the samples was calculated using the well-known Tauc relation [23, 24]:

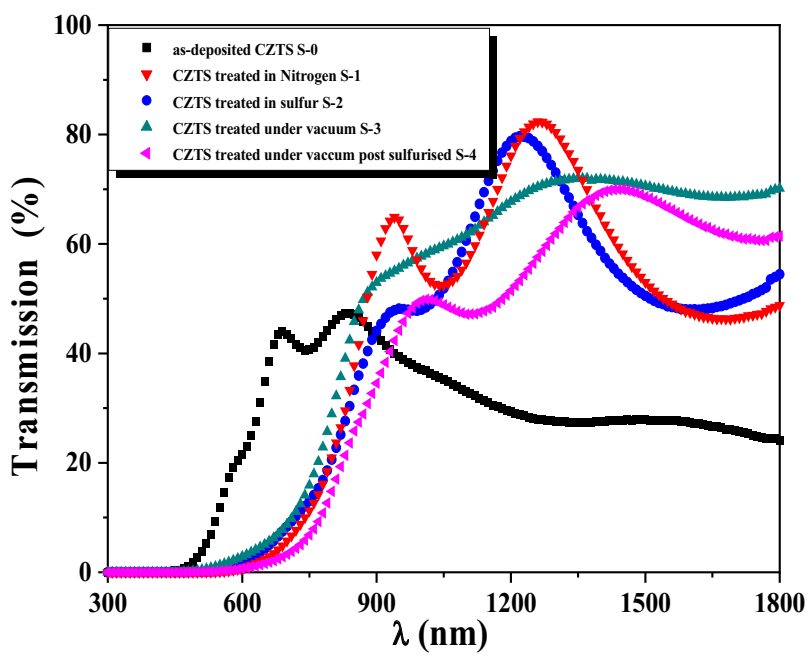

Fig. 4 Transmission spectra of CZTS thin films annealed under different atmospheres

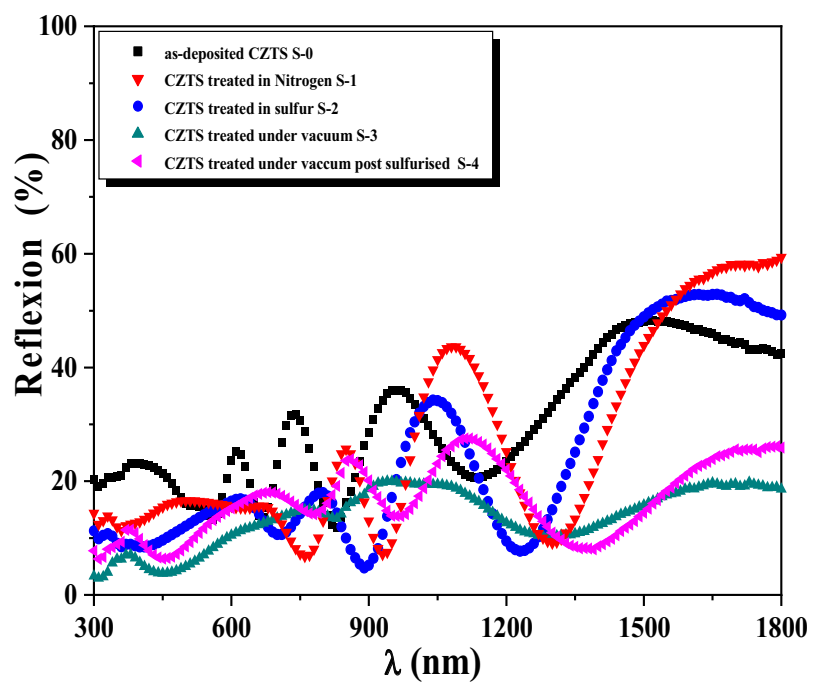

Fig. 5 Reflexion spectra of CZTS thin films annealed under different atmospheres

$(\alpha h \nu)^{2}=A\left(h v-E_{g}\right)$

In this equation, $a$ is the absorption coefficient, $h$ is the Planck constant, $v$ is the frequency of the incident beam, $A$ is a constant that depends on the transition probability and $E_{\mathrm{g}}$ is the optical energy gap. Figure 7 showed the behavior of $(a h v)^{2}$ versus photon energy $(h v)$ for the annealed CZTS thin films. The band gap of the CZTS films is determined by extrapolating the linear part of the (ahu) ${ }^{2}$ versus hu plot to the intercept of the photon energy axis. All the determined values of the band gap energy and the thickness are summarized in Table 2.

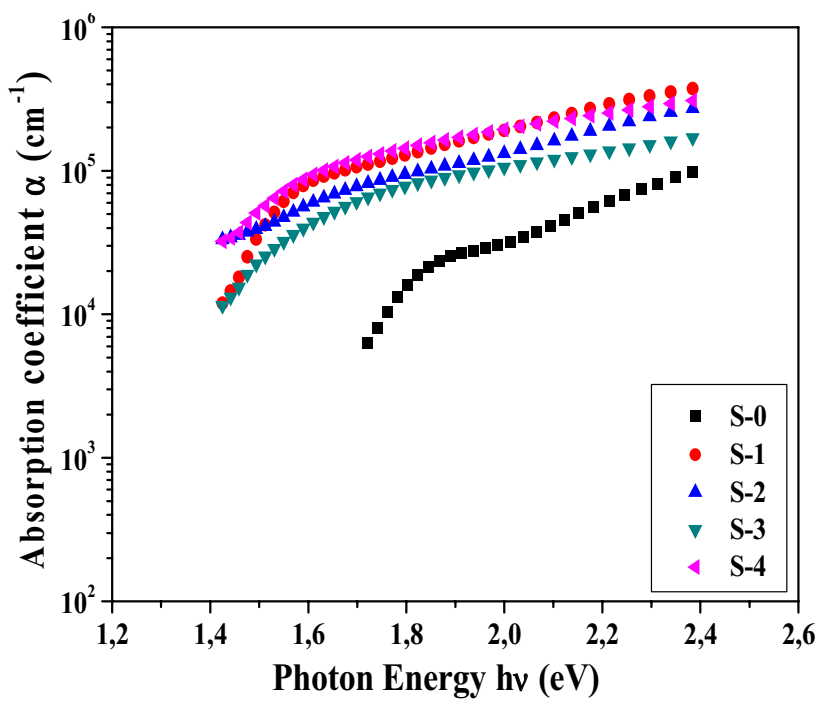

Fig. 6 Absorption coefficient of CZTS thin films annealed under different atmospheres 


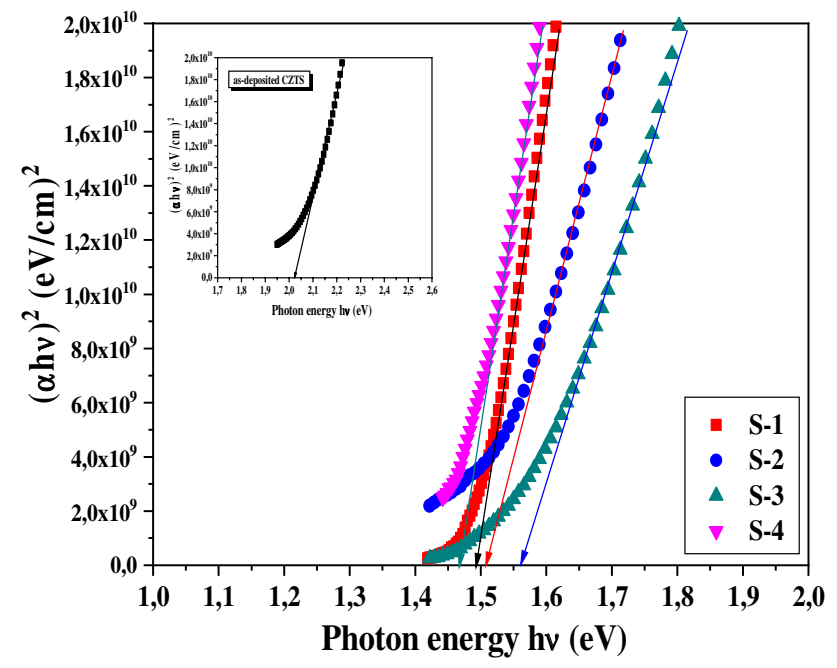

Fig. 7 (ahu) $)^{2}$ plot vs. (hu) of CZTS thin films

Table 2 Optical properties of CZTS thin films annealed under different atmospheres

\begin{tabular}{lll}
\hline Annealed samples & \multicolumn{2}{l}{ Optical properties } \\
\cline { 2 - 3 } & Thickness $(\mathrm{nm})$ & Band gap $(\mathrm{eV})$ \\
\hline S-1 & 210 & 1.49 \\
S-2 & 247 & 1.50 \\
S-3 & 293 & 1.56 \\
S-4 & 216 & 1.48 \\
\hline
\end{tabular}

\section{Discussions}

\subsection{Structural properties of $\mathrm{Cu}_{2} \mathrm{ZnSnS}_{4}$ powder}

According to the Fig. 2, the CZTS powder was polycrystalline in nature with a preferential orientation along the (112) plane. The analysis of the XRD pattern revealed that the main peaks located at $18.24,28.51,32.92,47.29$, $56.12,58.83$ and $69.13^{\circ}$ are related to the (101), (112), (200), (220), (312), (224) and (008) planes, respectively. These values are in good agreement with the values reported by Joint Committee on Powder Diffraction Standards (JCPDS card No. 26-0575). Camara et al. [25] have elaborated CZTS nanoparticles using hydrothermal method. The structural analysis has revealed a perfect similarity with our work for $(2: 1: 1: 4)$ ratio which proves the existence of the kesterite phase of CZTS. We also calculated the lattice parameters of the powder and we found $\mathrm{a}=5.43 \AA$ and $\mathrm{c}=10.91 \AA$. These values are in good with the values reported elsewhere $[26,27]$.

These results show that we succeeded in the fabrication of pure and monophase CZTS powder. This success is very important because this powder will be used as raw material to elaborate CZTS thin films.

\subsection{Structural properties of $\mathrm{Cu}_{2} \mathrm{ZnSnS}_{4}$ thin films}

As is seen in Fig. 3, we remark an interesting transformation from an amorphous aspect for the as-deposited sample to a polycrystalline structure for all annealed thin films. The amorphous nature of as-deposited CZTS films was also reported by Peksu et al. [28] for CZTS elaborated by e-beam evaporation. It is well seen that the (112) orientation is the dominant for all the CZTS films.

\subsection{Optical properties of $\mathrm{Cu}_{2} \mathrm{ZnSnS}_{4}$ thin films}

As seen for both transmission and reflexion spectra, the presence of an oscillatory behaviour reflects a high optical quality and homogeneity of our annealed samples. Also, we notice an important increase in the transmittance rate of the annealed samples (60-80\%) in comparison with the transmittance of the as-deposited thin film (40\%). The improvement of the transmittance of the annealed films can be correlated to the improvement of the structural properties. Indeed, the improvement of the crystalline quality will decrease the number of defects and grain boundaries in the film, which minimizes the scattering of light leading to high optical transmittance [34]. This result is consistent with that reported by Islam et al. [35]. High absorption coefficient (over than $10^{4} \mathrm{~cm}^{-1}$ ) is one of the most important criteria to consider in choosing an absorber layer in thin film solar cells. In our case, all annealed films showed a high absorption coefficient larger than $10^{4} \mathrm{~cm}^{-1}$.

It is clear that the annealing process improved the crystalline quality of films. However, the XRD measurements revealed the presence of many secondary phases such as $\mathrm{SnS}, \mathrm{Cu}$ and $\mathrm{Cu}_{4} \mathrm{SnS}_{4}$ for the samples annealed under $\mathrm{N}_{2}$ atmosphere (sample $\mathrm{S}-1$ ) and under $\mathrm{N}_{2}+\mathrm{S}_{2}$ atmosphere (sample S-2) whereas we obtained a pure CZTS phase with no secondary phases for the samples annealed under vacuum (sample S-3) and under sulfur atmosphere followed by vacuum annealing (Sample S-4).

Indeed, for the samples S-1 and S-2, we noticed the appearance of several peaks from SnS phase (JCPD card No. 00-001-0984) at $31.29^{\circ}$ and $39.12^{\circ}$ attributed to diffraction planes (013) and (104), the $\mathrm{Cu}_{4} \mathrm{SnS}_{4}$ phase (JCPD card No. 00-027-0196) located at $2 \theta=26.33^{\circ}$ and $27.54^{\circ}$ corresponding to (220) and (002) and CUS phase (JCPDS card No. 98-004-1975) at $43.40^{\circ}$ and $50.55^{\circ}$ corresponding to (111) and (200) diffraction planes. Kumar et al. [29] have elaborated CZTS by sol-gel method. After sulfuration of the samples at 300 and $450{ }^{\circ} \mathrm{C}$, they detected the presence of $\mathrm{Cu}_{x} \mathrm{~S}$ and $\mathrm{SnS}$ secondary phases in CZTS films. 
Balaji et al. [30] have elaborated CZTS films by Radio Frequency Magnetron Sputtering. After sulfuration at $350^{\circ} \mathrm{C}$, they noticed the presence of $\mathrm{SnS}$ secondary phase. It is obvious from these results that vacuum annealing (alone or combined with other annealing process) plays a crucial role in eliminating the secondary phases in CZTS thin films.

High absorption coefficient (over than $10^{4} \mathrm{~cm}^{-1}$ ) is one of the most important criteria to consider in choosing an absorber layer in thin film solar cells. In our case, all annealed films showed a high absorption coefficient larger than $10^{4} \mathrm{~cm}^{-1}$.

According to the structural parameters summarized in Table 1, the lattice parameter values match well with those reported in the literature [31]. The crystallite sizes of annealed samples varied between 29.01 and $37.95 \mathrm{~nm}$. Diwate et al. [30] have elaborated CZTS thin films using spray method. They calculated a value of $8.93 \mathrm{~nm}$ for the crystallite size which is lower than our values.

Furthermore, the increase of the crystallite size induces the decrease of the strain and the dislocation density. The best structural values were found for the CZTS films annealed under sulfur atmosphere followed by vacuum annealing (Sample S-4) with the highest crystallite size $37.95 \mathrm{~nm}$ and the lowest dislocation density and microstain, respectively, $6.94 .10^{14} \mathrm{~m}^{2}$ and 0.21 . This result is important because the efficiency of CZTS solar cells increases with the increase in the grain size and the crystalline quality of the absorber [31].

Indeed, a lot of researches have proved the positive effect of the increase in grain size on the chemical composition of CZTS compound such as Xiong et al. [32] who have concluded that the best grain size was found for CZTS thin films sulfurized at $600{ }^{\circ} \mathrm{C}$ corresponding to $\mathrm{Cu}, \mathrm{Zn}, \mathrm{Sn}$, and $S$ ratios: 4.8:2.6:1.8:10.4 which are remarkably close to the ideal stoichiometric ratio according to the literature [33].

Therefore, better crystalline quality is a very important criterion for highly efficient solar cells [31].

This result also leads to an important conclusion: the annealing under sulfur atmosphere followed by vacuum annealing is the best annealing treatment in order to obtain pure thermally evaporated CZTS films with high crystalline quality.

This result is very important for thin film photovoltaic applications. We note that the highest values were obtained for the samples annealed under $\mathrm{N}_{2}$ atmosphere (sample S-1) and under sulfur atmosphere followed by vacuum annealing (Sample S-4). The values obtained in this work were higher than those calculated by Rawat et al. [36] for CZTS fabricated by spin coating method and in good agreement with those obtained by Deokate et al. [37].

The as-deposited CZTS film had a relatively high band gap (2.2 eV). However, after annealing under different atmosphere, the band gap of annealed CZTS decreased from $2.2 \mathrm{eV}$ to a value around $1.5 \mathrm{eV}(1.48-1.56 \mathrm{eV})$ which make us conclude that thermal treatment has clearly improved the optical properties of our samples. The same behaviour of the band gap energy was reported by Vanalakar et al. [38]. Indeed, they fabricated $\mathrm{Cu}_{2} \mathrm{ZnSnS}_{4}$ thin films by pulsed laser deposition and they found that $E_{\mathrm{g}}$ decreases from $1.83 \mathrm{eV}$ (as-deposited film) to $1.53 \mathrm{eV}$ after annealing under different atmospheres [39]. The decrease of optical band gap after annealing may be due to the improvement of the crystalline quality induced by the annealing under different atmospheres. Indeed, according to the previous works, the optical band gap of CZTS thin films is correlated with different structural properties such as grain size and crystalline phase [23]. Thus, it is clear that the growth of the grain size of CZTS samples after annealing process has obviously reduced the band gap energy to the optimum. Also, Malerba et al. [39] explained the decrease of $E_{\mathrm{g}}$ by the deviations from stoichiometry and more precisely the variation of the $[\mathrm{Cu}] /[\mathrm{Sn}]$ ratio in CZTS thin films. According to the Shockley-Queisser work, the absorber layer must have an optimal bandgap (1.2-1.5 eV) to achieve the maximum conversion efficiency in thin film solar cells [40]. So, the band gap energy of the annealed CZTS films match the optimum value for solar photovoltaic applications.

The calculations of uncertainty of CZTS thin films' thickness were found in order of $0.075 \mathrm{~nm}$. Similarly, the band gap uncertainty was found in the range of $0.016 \mathrm{~nm}$ and $0.026 \mathrm{~nm}$.

\section{Conclusion}

In summary, the CZTS thin films were deposited by thermal evaporation under vacuum. Then, we carried out an annealing under different atmospheres. The XRD results showed a great improvement of the crystalline quality after annealing with a preferential orientation (112) and the absence of any secondary phase for the samples annealed under vacuum and under sulfur atmosphere followed by vacuum annealing. The optical study was investigated using UV-Vis spectrophotometer. The experimental results showed a high absorption coefficient and a decrease of the band gap from 2.2 to $1.5 \mathrm{eV}$ after the annealing process. It is worthwhile to mention that the CZTS thin film annealed under sulfur atmosphere followed by vacuum annealing had the best structural and optical properties as an absorber layer for solar cell application.

With the fact that CZTS material is only constituted by safe, cheap and earth abundant elements, CZTS films have important properties that fulfill the requirements of light absorber layer, such as high cristallinity, high absorption 
coefficient and optimal band gap. Thus, CZTS is a serious candidate as absorber layer in earth abundant solar cells.

\section{Compliance with ethical standards}

Conflict of interest The author declares that they have no conflict of interest.

\section{References}

1. Hashmi G, Hasan MS, Haque Efat MM, Rahman MH (2019) Portable solar panel efficiency measurement system. SN Appl Sci 2:115

2. Green MA, Hishikawa Y, Dunlop ED, Levi DH, Hohl-Ebinger J, HoBaillie AWY (2018) Solar cell efficiency tables (version 51). Prog Photovolt Res Appl 26:427-436

3. Grandell L, Höök M (2015) Assessing rare metal availability challenges for solar energy technologies. Sustainability 7:11818-11837

4. Khemiri N, Chamekh S, Kanzari M (2020) Properties of thermally evaporated CZTS thin films and numerical simulation of earth abundant and non-toxic CZTS/ZN(S, O) based solar cells. Sol Energy 207:496-502

5. Tumbul A (2020) Improving grain size and surface roughness of chemically derived Cu2CoSnS4 (CCTS) solar absorber material by controlling of $\mathrm{Cu} / \mathrm{Co}$ ratios. Ceram Int 46:289-296

6. Oueslati H, Ben Rabeh M, Kanzari M (2020) Synthesis and characterization of next generation Cu2ZnxFe1-xSnS4 ( $x=0,0.25$, $0.5,0.75$, and 1) compounds. J Electron Mater 49:627-636

7. Muhunthan N, Kuldeep G, Nand SV (2020) Sputtered cadimium sulphide (CDS) buffer layer for kesterite and chalcogenide thin film solar cell (TFSC) applications. J Nanosci Nanotechnol 20:3909-3912

8. Chtouki T, Soumahoro L, Kulyk B, Bougharra H, Erguig $H$, Ammous K, Sahraoui B (2017) Comparative study on the structural, morphological, linear and nonlinear optical properties of CZTS thin films prepared by spin-coating and spray pyrolysis. Mater Today Proc 4:5146-5153

9. Olgar MA, Bacaksiz E, Tomakin M, Meroglu TK, Basol BM (2019) CZTS layers formed under sulphur-limited conditions at above atmospheric pressure. Mater Sci Semicond Process 90:101-106

10. Jiang F, Ikeda S, Hadara T, Matsumuru M (2014) Pure sulfide, " $\mathrm{Cu}_{2} \mathrm{ZnSnS}_{4}$ thin film solar cells fabricated by preheating an electrodeposited metallic stack". Adv Energy Mater 4:1301381

11. Ismail Fathima M, Arulanantham AMS, Joseph Wilson KS (2020) Effect of ZnS nanowire arc on CZTS/CDS thin film solar cell by Nebulizer spray pyrolysis technique. Mater Res Express 7:015510

12. Jacob J, Ashfaq A, Tamseel M, Mahmood K, Amin N, Hussain S, Ahmad W, Rehman U, Ikram S, Al-Othmany DS (2019) Modulation of structural, optical and thermoelectric properties of solgel grown CZTS thin films by controlling the concentration of zinc. Ceram Int 45:12820-12824

13. Akcay N, Zaretskaya EP, Ozcelik S (2019) Development of a CZTS solar cell with CdS buffer layer deposited by RF magnetron sputtering. J Alloy Compd 772:782-792

14. Aydin R, Akyuz I (2020) Two-stage production and characterization of Cu-poor kesterite CZTS absorber layers. Optik 200:163407

15. Hong K, Xie M, Hu R, Wu H (2007) Synthesizing tungsten oxide nanowires by a thermal evaporation method. Appl Phys Lett 90:173121
16. Olgar MA (2019) Optimization of sulfurization time and temperature for fabrication of $\mathrm{Cu}_{2} \mathrm{ZnSnS}_{4}$ (CZTS) thin films. Superlattices Microstruct 126:32-41

17. Shin SW, Pawar SM, Park CY, Yun JH, Moon JH, Kim JH, Lee JY (2011) Studies on $\mathrm{Cu}_{2} \mathrm{ZnSnS}_{4}$ (CZTS) absorber layer using different stacking orders in precursor thin films. Sol Energy Mater Sol Cells 95:3202-3206

18. Hannachi A, Oueslati $\mathrm{H}$, Khemiri N, Kanzari M (2017) Effects of sulfurization on the optical properties of $\mathrm{Cu}_{2} \mathrm{Zn}_{\mathrm{x}} \mathrm{Fe}_{1-\mathrm{x}} \mathrm{SnS}_{4}$ thin films. Opt Mater 72:702-709

19. Jbara HB, Abdelkader D, Akkari FC, Kanzari M, Yazdi MAP, Billard A (2019) Preparation of $\mathrm{Cu}-\mathrm{Fe}-\mathrm{O}$ thin films via post oxidation of iron/copper bilayers: structural, optical and electrical properties. Opt Quant Electron 51(4):99

20. Tala-Ighil R, Haouanoh D, Toubane M, Bensouici F, Priyajith Samantilleke A, Slimani AV (2019) Structural, optical properties of CZTS layers deposited by spray pyrolysis technique. In: 31 st European photovoltaic solar energy conference and exhibition

21. Johnson H, Mohanraj K, Sivakumar G (2016) Electrical and optical properties of CZTS thin films prepared by SILAR method. J Asian Ceram Soc 4:81-84

22. Henry J, Mohanraj K, Sivakumar G (2016) Electrical and optical properties of CZTS thin films prepared by SILAR method. J Asian Ceram Soc 4(1):81-84

23. Touati R, Ben Rabeh M, Kanzari M (2015) Effect of post-sulfurization on the structural and optical properties of $\mathrm{Cu}_{2} \mathrm{ZnSnS}_{4}$ thin films deposited by vacuum evaporation method. Thin Solid Films 582:198-202

24. Feng J, Huang $X$, Chen W, Wu J, Lin H, Cheng Q, Zhang F (2016) Fabrication and characterization of $\mathrm{Cu}_{2} \mathrm{ZnSnS}_{4}$ thin films for photovoltaic application by low-cost single target sputtering process. Vacuum 126:84-90

25. Camara SM, Wang L, Zhang X (2013) Easy hydrothermal preparation of $\mathrm{Cu}_{2} \mathrm{ZnSnS}_{4}$ (CZTS) nanoparticles for solar cell application. Nanotechnology 24:9

26. Kapusta K, Drygas M, Janik JF, Jelen P, Bucko MM, Olejniczak Z (2019) From magnetic cubic pre-kesterite to semiconducting tetragonal kesterite $\mathrm{Cu}_{2} \mathrm{ZnSnS}_{4}$ nanopowders via the mechanochemically assisted route. J Alloy Compd 770:981-988

27. Das S, Sa K, Mahakul PC, Raiguru J, Alam I, Subramanyam B, Mahanandia P (2018) Synthesis of quaternary chalcogenide CZTS nanoparticles by a hydrothermal route. IOP Conf Ser Mater Sci Eng 338:012062

28. Peksu E, Terlemezoglu M, Parlak M, Karaagac H (2019) Characterization of one-step deposited $\mathrm{Cu}_{2} \mathrm{ZnSnS}_{4}$ thin films derived from a single crystalline powder. Renew Energy 143:1133-1142

29. Kumar J, Ingole S (2019) Evolution of the microstructural, electrical and optical characteristics of sol gel derived $\mathrm{Cu}_{2} \mathrm{ZnSnS}_{4}$ thin films during sulfurization. Mater Sci Semicond Process 91:31-40

30. Balaji G, Prabavathy N, Balasundaraprabhu R, Prasanna S, Echeverria E, Mcllroy DN, Sivakumaran K, Kannan MD, Velauthapillai $\mathrm{D}$ (2020) Investigations on post sulphurised $\mathrm{Cu}_{2} \mathrm{ZnSnS}_{4}$ absorber layer thin films prepared using radio frequency magnetron sputtering. Thin Solid Films 695:137764

31. Awadallah O, Chenga Z (2018) Synthesis, processing, and fundamental phase formation study of CZTS films for solar cell applications. Solar Energy Mater Solar Cells 176:222-229

32. Khemiri N, Kanzari M (2018) Determination and analysis of optical constants and dispersion energy parameters of $\mathrm{Zn}(\mathrm{S}, \mathrm{O})$ thin films. Mater Chem Phys 214:185-191

33. Islam MA, Rahman KS, Haque F, Akhtaruzzaman M, Alam MM, Alothman ZA, Sopian K, Amin N (2014) Properties of low temperature vacuum annealed czts thin films deposited on polymer substrate. Chalcogenide Lett 11:233-239 
34. Xiong C, Gao M, Gao W (2020) $\mathrm{Cu}_{2} \mathrm{ZnSnS}_{4}$ (CZTS) thin films prepared by sol gel spin-coating technique. Int J f Mod Phys 33:2040019

35. Lin YP, Chi YF, Hsieh TE, Chen YC, Huang KP (2016) Preparation of $\mathrm{Cu}_{2} \mathrm{ZnSnS}_{4}$ (CZTS) sputtering target and its application to the fabrication of CZTS thin-film solar cells. J Alloy Compd 654:498-508

36. Rawat K, Shishodia PK (2018) Thermal annealing induced modification on structural and optical properties of $\mathrm{Cu}_{2} \mathrm{ZnSnS}_{4}$ thin films for solar cell application. Superlattices Microstruct 122:444-452

37. Deokate RJ, Kate RS, Bulakhe SC (2019) Physical and optical properties of sprayed $\mathrm{Cu}_{2} \mathrm{ZnSnS}_{4}$ (CZTS) thin film: effect of $\mathrm{Cu}$ concentration. J Mater Sci Mater Electron 30:3530-3538
38. Vanalakar SA, Shin SW, Agawane GL, Suryawanshi MP, Gurav KV, Patil PS, Kim JH (2014) Effect of post annealing atmosphere on the grain size and surface morphological properties of pulsed laser deposited CZTS thin films. Ceram Int 40:15097-15103

39. Malerba C, Biccari F, Müller M, Santoni A, Esposito E, Mangiapane P, Scardi P, Mittiga A (2014) CZTS stoichiometry effects on the band gap energy. J Alloy Compd 582:528-534

40. Nasti G, Abate A, Halide T (2019) Perovskite (ASnX3) solar cells: a comprehensive guide toward the highest power conversion efficiency. Adv Energy Mater 58:130-137

Publisher's Note Springer Nature remains neutral with regard to jurisdictional claims in published maps and institutional affiliations. 